\title{
Surgical management of coexisting corneal and lens opacities: one-stage vs two-stage approach
}

\author{
Ali G. Ali, Basyoni O. El-Shabrawy, Abd E.A.A. Elsabour, Bor'i A. Mohamed
}

Department of Ophthalmology, Faculty of Medicine, Zagazig University, El Sharkia, Zagazig, Egypt

Correspondence to Ali G. Ali.

Tel: +20 1149880064 .

e-mail: aligoda85@yahoo.com

Received: July 2019

Revised: July 2019

Accepted: August 2019

The Egyptian Journal of Cataract and Refractive Surgery 2019

\begin{abstract}
Purpose
The aim was to compare the refractive and visual outcome of the triple procedure and the sequential surgery and to report any adverse effects or complications of each approach.
\end{abstract}

\section{Patients and methods}

Forty eyes of 40 patients with corneal opacity and visually significant cataract were divided into two equal groups: the triple group (group I) and the sequential group (group II). In group I, patients underwent PKP with cataract extraction by either open sky ECCE technique or phacoemulsification according to the degree of corneal clarity. In group II, patients first underwent PKP then scheduled for phacoemulsification and intraocular lens implantation. All patients were followed up for 1 year, and data including the visual acuity, refractive outcome, ECC and complications were recorded and analyzed.

Pkp penetrating keratoplasty ECCE extracapsular catarct extraction

Results

After 1 year of follow-up, the mean best corrected visual acuity (BSCVA) was 0.35 \pm 0.13 , with $45 \%$ of eyes with BSCVA greater than or equal to 0.5 in group I. In group II, the mean BSCVA was $0.52 \pm 0.12(P=0.021)$, with $60 \%$ of eyes with BSCVA greater than or equal to $0.5(P=0.14)$. Mean spherical equivalent after triple procedure was $-1.6 \pm 0.2 \mathrm{D}$. Mean spherical equivalent following sequential surgery was $-0.29 \pm 0.24 \mathrm{D}(P=0.00)$. The mean cylinder after combined surgery was $-3.85 \pm 1.21$, compared with $-3.45 \pm 0.82 \mathrm{D}$ after sequential surgery $(P=0.231)$. Overall, $50 \%$ of group I and $70.0 \%$ of group II patients were within $\pm 2 \mathrm{D}$ of the target refraction $(P=0.19)$. No significant difference in the mean ECC was found at the end of follow-up period $(P=0.524)$.

\section{Conclusion}

Planned phacoemulsification after PKP is a safe and effective approach for management of coexisting lens and corneal opacity.

Keywords:

corneal opacity and cataract, sequential surgery, triple procedure

\section{Introduction}

Many patients especially elderly people with corneal diseases necessitating PKP also require cataract surgery. However, there is controversy, with some surgeons preferring the triple procedure (combined PKP and cataract extraction and IOL implantation) [1-3], whereas others favoring sequential surgery (PKP followed by cataract surgery later on) $[4,5]$.

The triple procedure became popular because it offers the potential of more rapid visual rehabilitation. Moreover, one procedure can preserve the graft endothelial cells during cataract extraction [6]. However, difficulties in predicting postkeratoplasty corneal power has become apparent especially in case of corneal diseases that affect the corneal refractive power, such as keratoglobus or keratoconus. In other patients, it is impossible to obtain measurable and reliable keratometry values, and therefore, it is necessary to apply standard biometric values [7].

On the contrary, sequential surgery may result in a better refractive outcome. In addition, sequential surgery has an opportunity to correct postkeratoplasty astigmatism by performing arcuate keratotomies or using a toric IOL. To achieve this goal, cataract extraction should be delayed for at least 6 months after penetrating keratoplasty procedure. During this period, sutures can be removed, and graft curvature is stabilized [1]. However, two-stage surgeries have the disadvantages of late visual rehabilitation, the cost and risks of a second

This is an open access journal, and articles are distributed under the terms of the Creative Commons Attribution-NonCommercial-ShareAlike 4.0 License, which allows others to remix, tweak, and build upon the work non-commercially, as long as appropriate credit is given and the new creations are licensed under the identical terms. 
anaesthesia, and decrease in the endothelial cell count in the donor graft [6].

\section{Patients and methods}

Eyes with corneal pathology necessitating PKP and had co-exiting visually significant cataract were included in this study. During the study period from July 2016 to June 2019, 40 eyes of 40 patients were included in the study as a comprehensive sample. They were divided into two equal groups: the combined group (group I) and the sequential group (group II). Patients with retinal disorders, patients with uncontrolled glaucoma, patients with active or previous uveitis, patients with stem cell deficiency, and patients with active keratitis or corneal melting were excluded. The protocol was reviewed and approved by the Ethics Committee of Zagazig University Hospital before initiating this study (IRB \#: 2809/6-4-2016).

All patients were subjected to preoperative assessment with complete medical and ophthalmic examination, including uncorrected visual acuity (UCVA), refraction (whenever possible), best spectaclecorrected visual acuity (BCVA) presented by the decimal notation, slit-lamp examination, retinal evaluation and tonometry using applanation tonometry, corneal topography using Sirius 3D Rotating Scheimpflug Camera and Topography System with software suite Phoenix v2.1 (Costruzione Strumenti Oftalmici, Florence, Italy), and biometry using either A-scan ultrasonography (Digital A/B scan 5500; Sonomed Inc., Lake Success, New York, USA) or IOLMaster 500 (Carl Zeiss Meditec AG, Jena, Germany). IOL power calculation was done by SRK/T formula using a standard constant keratometry value of $44 \mathrm{D}$ in the triple group, and the actual kertometric values form the corneal topography of the transplanted cornea in the sequential group (emmetropia was targeted in all eyes). Corneal endothelial cell count was estimated by specular microscope CEM-530 (Nidek Co. Ltd, Gamagori, Japan). The degree of cataract was categorized based on the LOCS III [8].

\section{The triple procedure}

Under general anaesthesia and after pupillary dilation, PKP procedure was performed using the standard technique. A Barron suction trephine (CORONET; Network Medical Products, North Yorkshire, UK) was centered over the central corneal mark and suction applied. After the trephine was removed, the wound was inspected, and the AC entered with a sharp blade.
The $\mathrm{AC}$ was reinflated with viscoelastic material to maintain the integrity of the eyeball, and the corneal scissors were used to remove the recipient cornea. The donor cornea was punched out from the endothelial side with diameters ranging from 7.25 to $8 \mathrm{~mm}$ using the Barron donor punch (CORONET; Network Medical Products). Donor recipient disparity was $0.25 \mathrm{~mm}$ in keratoconic eyes and $0.5 \mathrm{~mm}$ in other conditions. Cataract extraction was done by either open sky ECCE or phacoemulsification according to the degree of corneal clarity. The suturing technique consisted of 16 bite interrupted 10-0 nylon suture.

\section{The sequential surgery}

Patients in this group first underwent PKP as described, except that topical mydriatic was not used to dilate the pupil. Phacoemulsification and IOL implantation was scheduled for at least 6 months after PKP. Phacoemulsification was performed under peribulbar anesthesia. Main incision was made outside the graft. The anterior chamber was filled with OVD, and CCC was performed with a capsulorhexis forceps. After hydrodissection, phacoemulsification was performed by the stop and chop technique. Then a foldable acrylic hydrophilic IOL was inserted within the capsular bag.

\section{Postoperative follow up}

All eyes received antibiotic and steroid eye drops and other topical medications (such as for glaucoma) as appropriate. All patients were scheduled for follow-up and postoperative evaluation at 1 day, 3 days, 1 week, 1 month, and 3 months postoperatively and then every 3 months for 1 year. On each visit, BCVA, autorefractometer readings whenever possible, slit lamp examination, and tonometry were performed.

If astigmatism was more than 4 Diopter during the follow-up, it was treated in the third month postoperatively by selective suture removal guided by the corneal topography.

\section{Statistical analysis}

Data were statistically analyzed using the Statistical Package for the Social Sciences (SPSS version 20.0) software. $\chi^{2}$-Test was used to test differences for significance of qualitative variable. Differences between quantitative independent groups were tested by $t$-test or Mann-Whitney $U$-test, and paired by paired $\mathrm{t}$ or sign. $P$ value was set at less than 0.05 for significant results and less than 0.001 for highly significant result. 


\section{Results}

In group I, nine (45\%) males and 11 (55\%) females were included, and for group II, eight males and 12 females were included in a percent of 40 and $60 \%$, respectively $(P=0.74)$. The mean age for group I was $55.4 \pm 14.38$ years (range: $21-75$ years), whereas the mean age for group II was $54.35 \pm 13.66$ years (range: 21-67 years) $(P=0.814)$ (Table 1$)$.

There were 12 (60\%) eyes with corneal scars in group I, whereas in groups II, there were $12(60 \%)$ eyes with corneal scars $(P=0.61)$. Five $(25 \%)$ eyes were diagnosed clinically to have corneal dystrophy in group I. Moreover, there were six (30\%) eyes with corneal dystrophy in group II $(P=0.53)$. Advanced keratoconus was present in three (15\%) eyes in group I and two (10\%) eyes in group II $(P=0.42)$.

In group I, open sky ECCE was performed in 18 (90\%) eyes, whereas phacoemulsification followed by PKP was done in two (10\%) eyes: one eye was diagnosed with keratoconus, and the other one had corneal scar from previous trauma.

In the ECCE subgroup, after successful trephination, trypan blue was used to stain the capsule in all cases expect one eye which had a very good red reflex. Narrow pupil owing to previous synechia especially in cases with previous infectious keratitis was released mechanically. Extended capsulorhexis was encountered in two (10\%) eyes, which were completed with scissors followed by successful nucleus delivery in all cases. Delivery was performed by irrigation in $16(70 \%)$ eyes and phacoprobe-assisted delivery in two (10\%) cases. No vitreous loss was encountered in any case, and rigid IOL was implanted in all cases. In phacoemulsification subgroup, foldable IOL was implanted in the bag without vitreous loss or capsular rupture.

Small incision phacosurgery was performed in all eyes in group II after stabilization of refraction. No vitreous loss was encountered, and foldable IOL was implanted in the bag in all cases.

Table 1 Age and sex distribution between the studied groups

\begin{tabular}{lcccc}
\hline & Group I & Group II & $t / \chi^{2}$ & $P$ \\
\hline Age & $55.4 \pm 14.38$ & $54.35 \pm 13.66$ & 0.237 & 0.814 \\
Sex $[n(\%)]$ & & & & \\
$\quad$ Female & $11(55.0)$ & $12(60.0)$ & 0.102 & 0.74 \\
Male & $9(45.0)$ & $8(40.0)$ & & \\
$\quad$ Total & $20(100.0)$ & $20(100.0)$ & & \\
\hline
\end{tabular}

Group I, the triple group; group II, the sequential group. $P>0.05$ is nonsignificant.
There was no statistically significant difference between the mean preoperative UCVA $(0.012 \pm 0.009$ in group I and $0.009 \pm 0.09$ in group II; $P=0.873$ ). In group I, the mean postoperative UCVA at the first, third, sixth, ninth month, and 1 year postoperatively was $0.03 \pm 0.017,0.058 \pm 0.018, \quad 0.098 \pm 0.032,0.14$ \pm 0.06 , and $0.21 \pm 0.07$, respectively. The mean postoperative UCVA in the second group at the same follow-up period was $0.04 \pm 0.02,0.11 \pm 0.041$, $0.19 \pm 0.06, \quad 0.24 \pm 0.09$, and $0.27 \pm 0.07$, respectively $(P=0.009)$ (Fig. 1).

The mean postoperative best corrected visual acuity (BSCVA) in the first group at first, third, sixth, ninth month, and 1 year postoperatively was $0.05 \pm 0.03,0.11$ $\pm 0.06, \quad 0.17 \pm 0.09, \quad 0.26 \pm 0.13$, and $0.35 \pm 0.13$, respectively. The mean postoperative BSCVA in the second group at the same follow-up periods was 0.27 $\pm 0.05,0.31 \pm 0.09,0.35 \pm 0.14,0.43 \pm 0.14$, and 0.52 \pm 0.12 , respectively $(P=0.021)$. The percentage of change was also significantly higher in group 1 $(P=0.00)$ (Fig. 2).

\section{Figure 1}

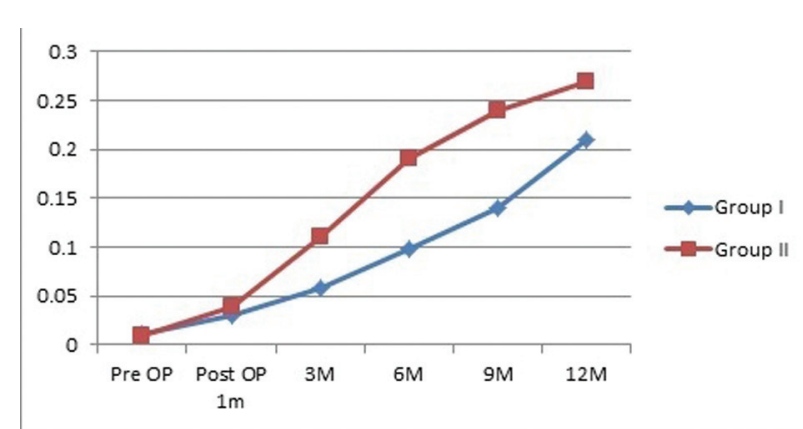

Line graph shows the mean preoperative uncorrected visual acuity and the uncorrected visual acuity at 1, 3, 6, and 9 months and 1 year postoperatively. Group I: the triple group. Group II: the sequential group.

Figure 2

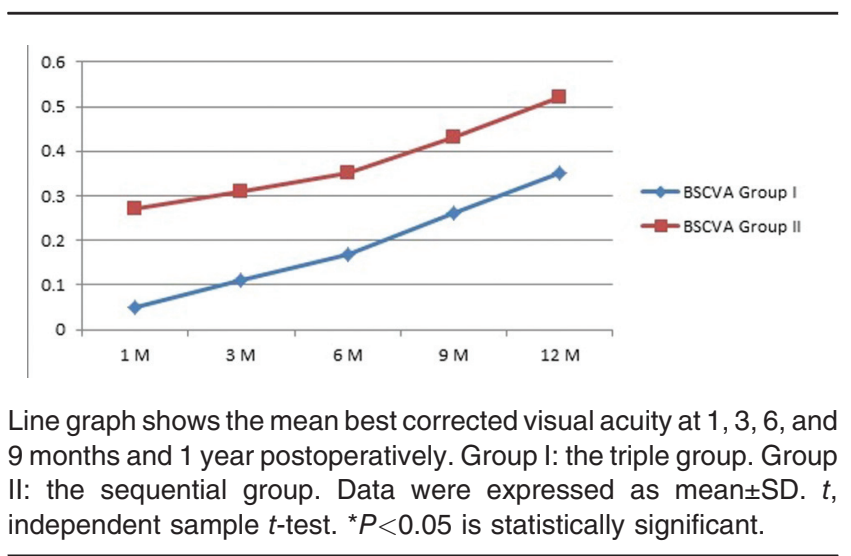


Table 2 Endothelial cell count distribution between the studied groups at different times

\begin{tabular}{|c|c|c|c|c|}
\hline & Group I & Group II & $t$ & $P$ \\
\hline ECC basal & $2684.6 \pm 187.5$ & $2701.5 \pm 197.3$ & 1.741 & 0.089 \\
\hline ECC before surgery (sequential group) & & $2151.2 \pm 240.2$ & & \\
\hline ECC post_1 month & $2189.2 \pm 180.19$ & $2021.7 \pm 140.09$ & 3.047 & $0.008^{*}$ \\
\hline ECC post_3 months & $2155.7 \pm 265.7$ & $1901.6 \pm 225.7$ & 2.242 & $0.038^{*}$ \\
\hline ECC post_6 months & $1909.2 \pm 250.6$ & $1829.0 \pm 225.56$ & 2.395 & $0.027^{*}$ \\
\hline ECC_post_9 months & $1781.0 \pm 258.8$ & $1704.0 \pm 212.2$ & 1.809 & 0.061 \\
\hline ECC_post_1 year & $1688.5 \pm 260.7$ & $1665.4 \pm 196.2$ & 0.643 & 0.524 \\
\hline Percentage of change & $35.65 \pm 5.85$ & $36.87 \pm 6.21$ & 2.874 & $0.002^{*}$ \\
\hline
\end{tabular}

ECC, endothelial cell count; group I, the triple group; group II, the sequential group. ${ }^{*} P<0.05$ is statistically significant.

There were nine (45\%) eyes with BSCVA greater than or equal to 0.5 in group I, and there were $12(60 \%)$ eyes with BSVA greater than or equal to 0.5 in group II $(P=0.14)$.

The postoperative mean spherical equivalent (MSE) in group I at first, third, sixth, ninth month, and 1 year postoperatively was $-4.72 \pm 1.26,-3.62 \pm 0.74,-2.5$ $\pm 0.56,-1.9 \pm 0.38$, and $-1.6 \pm 0.2$, respectively. The mean postoperative spherical equivalent in group II at the same follow-up periods was $-2.6 \pm 1.23,-1.7$ $\pm 0.71, \quad-0.8 \pm 0.51, \quad-0.43 \pm 0.4, \quad$ and $-0.29 \pm 0.24$, respectively $(P=0.00)$. Percentage of decrease was significantly higher among group $2(P=0.001)$.

The postoperative mean cylinder (MC) in group I at the first, third, sixth, ninth month, and 1 year postoperatively was $-6.41 \pm 1.57,-5.67 \pm 1.57,-5.17$ $\pm 1.44,-4.65 \pm 1.25$, and $-3.85 \pm 1.21$, respectively. The postoperative $\mathrm{MC}$ in group II at the same follow-up periods was $-5.12 \pm 0.62,-4.8 \pm 0.63,-4.05 \pm 0.79,-3.71$ \pm 0.75 , and $-3.45 \pm 0.82$, respectively. Although group II had a lower value, $P$ value between the two groups was 0.231 , which was statistically insignificant.

In this study, although the number of eyes within $\pm 2 \mathrm{D}$ of the target refraction was higher in the second group [10 (50\%) eyes in group I vs 14 (70\%) eyes in group II], this difference was not statistically significantly $(P=0.19)$.

There was no statistically significant difference between the mean ECC in the corneal graft implanted in both groups $(2684.6 \pm 187.5$ in group I vs $2701.5 \pm 197.3$ in group II; $P=0.089$ ). The mean ECC in the group I at the first, third, sixth, ninth month, and 1 year was $2189.2 \pm 180.19,2155.7 \pm 265.7$, $1909.2 \pm 250.6, \quad 1781.0 \pm 258.8$, and $1688.5 \pm 260.7$, respectively, whereas the mean ECC in the group II at the first, third, sixth, ninth month, and 1 year was $2021.7 \pm 140.09,1901.6 \pm 225.7,1829.0 \pm 225.56,1704.0$ \pm 212.2 , and $1665.4 \pm 196.2$, respectively. There was no statistically significant difference between the mean ECC at the end of the follow-up period in both groups $(P=0.524)$. Although the percentage of endothelial cell loss at the end of the follow-up period was higher in group II, there was no statistically significant difference between both groups $(P=0.412)$ (Table 2$)$.

There was early onset of PCO in one (5\%) eye in group I treated by Yag capsulotomy after 3 months, one (5\%) eye had captured IOL, and one (5\%) eye had residual lens matter and loose stitch. This patient was prepared for second intervention when removal of the residual lens matter was done by I/A, and the stitch was removed and wound was resutured. One (5\%) eye had an attack of endothelial rejection treated by intense topical and systemic steroid and subconjunctival triamcinolone acetonide injection. Apart from two (10\%) eyes that developed PCO, no postoperative complication was noted in group II. There was no significant association or difference regarding the distribution of complications $(P=0.34)$, but the overall complication was significantly associated with group $1(P=0.045)$.

\section{Discussion}

In many patients, the corneal opacity and cataract coexist. Such patients are commonly approached by performing the triple procedure or applying the sequential approach. In this study, the results between patients undergoing triple procedure and sequential surgery in terms of VA, refractive outcome, ECC, and complications were compared.

In this study, the mean postoperative BSCVA in the triple group at one year postoperatively was $0.35 \pm 0.13$, whereas the mean postoperative BSCVA in the sequential group at the same follow-up period was $0.52 \pm 0.12$. Cazabon et al. [2] in 2010 found similar results with mean postoperative BCVA was 0.40 in the triple procedure group and 0.588 in the sequential surgery group. 
Nine of 20 (45\%) eyes gained BSCVA greater than or equal to 0.5 in the triple group. Javadi, Feizi, and Moein in 2013 had comparable results, with $40.8 \%$ of eyes gained BSCVA greater than or equal to 0.5 [3]. Nguyen et al. [1] in a large retrospective study involved 858 triple procedures and found that $61 \%$ of eyes attained BCVA of greater than or equal to 0.5 . In the sequential group, 12 of 20 eyes (60\%) gained BSCVA greater than or equal to 0.5 . Hsiao et al. [4] reported BCVA greater than or equal to 0.5 in 21 (81\%) eyes after selective suture removal and performing relaxing corneal incisions in $23 \%$ of the cases.

Parmar et al. [9] reported final visual outcome, where 39 and $47 \%$ of their patient achieved BCVA greater than or equal to 0.5 in the triple and the sequential group, respectively; this can be explained by the indication of surgery which was therapeutic keratoplasty after infective ulcer, and the patient in the triple procedure had repeated keratoplasty.

The postoperative MSE was $-1.6 \mathrm{D}$ in the triple procedure group at the end of the follow-up period, whereas in the sequential group was $-0.29 \mathrm{D}$. The MSE was significantly lower in the sequential group. Nguyen et al. [1] in 2009 found similar results, with the MSE after 1 year of follow-up was 1.20 in the triple group and $0.08 \mathrm{D}$ in the sequential group. Gruenauer-Kloevekorn et al. [7] reported MSE of -2.06 after the triple procedure and 0.70 after sequential surgery.

This study revealed that $10(50 \%)$ eyes in the triple group were within $\pm 2 \mathrm{D}$ of emmetropia after 1 year of follow-up, and this compares favorably with other studies. Nguyen et al. [1] reported $47 \%$ of eyes achieved this after 1 year, with $55 \%$ achieving this at the end of the second year. Pineros et al. [10] reported $42 \%$ and Hayashi and Hayashi [5] had 39\% of the eyes within $\pm 2 \mathrm{D}$ of the target emmetropia.

A total of $14(70 \%)$ eyes in the sequential group achieved $\pm 2 \mathrm{D}$ of emmetropia at the end of the follow-up period. Other studies showed comparable results. Nguyen et al. [1] reported $67 \%$ of eyes achieved this after 1 year, with $50 \%$ achieving this at the end of the seocnd year. Lower percent in the second year was explained by the low numbers of eyes with complete follow-up data. Pineros et al. [10] reported that 48\% were within this value and Hayashi and Hayashi [5] had $70 \%$ of the eyes within $\pm 2 \mathrm{D}$ of the target emmetropia.
Geggel [11] performed IOL implantation alone at an average period of 11 months after PKP and ECCE. He reported that $95 \%$ of eyes were within $\pm 2 \mathrm{D}$ of emmetropia, but $59 \%$ of eyes in this series received astigmatic correction at the time of secondary surgery, and all graft corneal sutures had been removed in $86 \%$ of eyes. Moreover, Shimmura et al. [6] had similar results, with $91 \%$ of eyes were within $\pm 2 \mathrm{D}$ of emmetropia after manipulation of the single running suture placed at the time of PKP.

The $\mathrm{MC}$ at the end of follow up was $-3.85 \pm 1.21 \mathrm{D}$ in the triple group and $-3.45 \pm 0.82 \mathrm{D}$ in the sequential group. There was no statistically significant difference between both groups. Shimmura et al. [6] found that the manifest astigmatism at the end of follow-up was $3.4 \pm 1.1 \mathrm{D}$ in the triple group and $2.4 \pm 1.2 \mathrm{D}$ in the sequential group. Parmar et al. [9] reported an astigmatic error of $-4.0 \pm 1.6 \mathrm{D}$ in the triple procedure and $-2.7 \pm 0.8 \mathrm{D}$ in the sequential group, with no significant difference between the two groups. In contrast, Pineros et al. [10] in their comparative study revealed that the mean astigmatic error in the triple group was $3.9 \mathrm{D}$, whereas in the nonsimultaneous group was 4.1 D.

Toric IOL were not used in this study because they were not available in our institute. However, toric IOL should be considered in the management of the astigmatic error in the sequential group as reported by other studies $[12,13]$.

The mean ECC recorded from the graft before performing PKP in both groups was $2684.6 \pm 187.5$ and $2701.5 \pm 197.3$ in the triple and the sequential groups, respectively. Because ECC had already decreased by the time of sequential cataract surgery, the mean ECC was 2151.2 \pm 40.2 . The mean ECC measured at the end of follow-up period was 1618.5 \pm 260.7 in the triple group and $1665.4 \pm 196.2$ in the sequential group, with no significant difference between them. The percentage of endothelial cell loss in the first group after 1 year was $35.65 \pm 5.85 \%$, whereas in the second group was $36.87 \pm 6.21 \%$. Shimmura et al. [6] reported similar results with endothelial cell density measured at one year postoperatively was $1617 \pm 638$ in the secondary group and $1675 \pm 866$ in the triple group. It is worth noting that in this study, the surgeon used a cohesive viscoelastic, and the study was discontinued for ethical purpose with the introduction of dispersive viscoelastics, which offer a better endothelial protection. Hayashi and Hayashi [5] in their study 
ended with mean endothelial cell density of $1751 \pm 526$ in the simultaneous group and $1651 \pm 636$ with insignificant difference between both groups.In the sequential group, the ECC has already decreased by $20.3 \%$ by the time of cataract surgery; therefore, the endothelial density tended to be lower in the sequential group. However, the difference between the groups was not significant. The percentage of endothelial cell loss from that seen before cataract surgery was $11 \%$ at 3 months and $14.9 \%$ at 6 months, which was slight. These results indicate that secondary phacoemulsification surgery did not cause severe damage to the endothelial cells of the transplanted cornea. Hayashi and Hayashi [5] in 2006 reported $5.9 \%$ of endothelial cell loss at 3 months and $11.6 \%$ at 6 months after sequential surgery.

In the new approach suggested by Solaiman et al. [14] in 2019, simultaneous PKP and cataract surgery was done, followed by implantation of foldable three-piece acrylic IOL in the ciliary sulcus after removal of corneal sutures. They reported that the mean percentage of endothelial cell loss after IOL implantation was 7.3\% at 6 months. However, the mean interval between cataract extraction and secondary IOL implantation was $13.3 \pm 2.2$ months (range: $10-17$ months), whereas in this study, cataract extraction and IOL implantation was done early after 6 months, so our results were more affected by the continuous decline in ECC after PKP.

Surgeons who do not favor the combined approach claim that the intraoperative risks are higher compared with sequential surgery, particularly because the open sky period is longer. It is hard to determine the exact rate of vitreous loss and posterior capsule rupture associated with the triple procedure. Some studies report a posterior capsule tear rate as high as $15 \%$ and vitreous loss of $4-12 \%$ [15], whereas others have reported a posterior capsule rupture rate of less than $1 \%$ [16]. In a more recent study, they reported one (1.3\%) eye with vitreous loss following IOL implantation owing to positive vitreous pressure which necessitated automated anterior vitrectomy and exchange of the IOL with an angle-supported anterior chamber IOL [5]. In our study, despite limited patient number, we did not have any episodes of vitreous loss, posterior capsule rupture, or suprachoroidal hemorrhage in either group, so both procedures were equally safe.

\section{Financial support and sponsorship \\ Nil.}

\section{Conflicts of interest}

There are no conflicts of interest.

\section{References}

1 Nguyen DQ, Mumford LL, Jones MNA, Armitage WJ, Cook SD, Kaye SB, Tole DM. The visual and refractive outcomes of combined and sequential penetrating keratoplasty, cataract extraction, and intraocular lens insertion. Eye 2009; 23:1295-1301.

2 Cazabon S, Quah SA, Jones MN, Batterbury M, Kaye SB. Sequential versus combined penetrating keratoplasty and cataract surgery. Optom Vis Sci 2010; 87:482-486.

3 Javadi MA, Feizi S, Moein HR. Simultaneous penetrating keratoplasty and cataract surgery. J Ophthalmic Vis Res 2013; 8:39-46.

4 Hsiao $\mathrm{CH}$, Chen JJ, Chen PY, Chen HS. Intraocular lens implantation after penetrating keratoplasty. Cornea 2001; 20:580-585.

5 Hayashi K, Hayashi H. Simultaneous vs sequential penetrating keratoplasty and cataract surgery. Cornea 2006; 25:1020-1025.

6 Shimmura S, Ohashi Y, Shiroma H. Corneal opacity and cataract: triple procedure versus secondary approach. Cornea 2003; 22:234-238.

7 Gruenauer-Kloevekorn C, Kloevekorn-Norgall K, Duncker GI, Habermann A. Refractive error after triple and non-simultaneous procedures: is the application of a standard constant keratometry value in IOL power calculation advisable? Acta Ophthalmol Scand 2006; 84:679-683.

8 Chylack LT Jr, Wolfe JK. The lens opacities classification system III. Arch Ophthalmol 1993; 111:831836.

9 Parmar P, Salman A, Kalavathy CM, Thomas PA, Jesudasan CA. Outcome analysis of cataract surgery following therapeutic keratoplasty. Cornea 2005; 24:123-129.

10 Pineros OE, Cohen EJ, Rapuano CJ, Laibson PR. Triple vs nonsimultaneous procedures in Fuch's dystrophy and cataract. Arch Ophthalmol 1996; 114:525-528.

11 Geggel HS. Intraocular lens implantation after penetrating keratoplasty. Ophthalmology 1990; 97:1460-1467.

12 Wade M, Steinert RF, Garg S, et al. Results of toric intraocular lenses for post-penetrating keratoplasty astigmatism. Ophthalmology 2014; 121:771-777.

13 Lockington D, Wang EF, Patel DV, Moore SP, McGhee CNJ. Effectiveness of cataract phacoemulsification with toric intraocular lenses in addressing astigmatism after keratoplasty. J Cataract Refract Surg 2014; 40:2044-2049.

14 Solaiman KAM, El-Haig WM, BorÊ1/4i A, Khalil AS, Awad AMB, Al-Bialy HA, Ibrahim BM. Secondary intraocular lens implantation after simultaneous penetrating keratoplasty and cataract extraction for coexisting corneal and lens opacities. Cornea 2019; 38:397-402.

15 Crawford GJ, Stulting RD, Waring IIIGO, Van Meter WS, Wilson LA. The triple procedure: analysis of outcome, refraction, and intraocular lens power calculation. Ophthalmology 1986; 93:817-824.

16 Davis EA, Azar DT, Jakobs FM, Stark WJ. Refractive and keratometric results after the triple procedure. Ophthalmology 1998; 105:624-630.

17 Viestenz A, Kuchle M, Seitz B, Langenbucher A. Implantation of toric intraocular lenses for correction of high astigmatism after penetrating keratoplasty. Ophthalmologe 2005; 102:147-152. 